\title{
Evaluating the Highway Tunnel Construction in Western Sichuan Plateau Considering Vocational Health and Environment
}

\author{
Peng $\mathrm{Wu}{ }^{1}$, Feng Yang ${ }^{2, *}$, Jinlong Zheng ${ }^{2}$ and Yanqing Wei ${ }^{2}$ \\ 1 Department of Management Science and System Science, Sichuan University, 29 Wangjiang Road, \\ Chengdu 610064, China; pengwu@scu.edu.cn \\ 2 Sichuan Highway Planning, Survey, Design and Research Institute Ltd., 1 Wuhouci Hengjie Street, \\ Chengdu 610041, China; yf718866932@126.com (J.Z.); wayaqa@126.com (Y.W.) \\ * Correspondence: yangfeng1991@126.com
}

Received: 6 October 2019; Accepted: 18 November 2019; Published: 23 November 2019

\begin{abstract}
Oxygen deficiency and coldness are the main challenges for highway tunnel construction in high-altitude areas such as western Sichuan plateau. The artificial oxygen supply and anti-freezing structure in the tunnel construction process has a significant impact on vocational health and the environment. Thus, the conditions of tunnels need to be carefully evaluated before construction. However, the current design code for tunnel construction contains few instructions about these aspects. This paper attempts to establish a simple evaluation method to guide the construction design by analyzing the oxygen partial pressure of trachea, the mean temperature of the coldest month, and the maximum freezing depth for tunnel projects in western Sichuan plateau. Based on the on-site meteorological monitoring at different altitudes of three typical tunnels in the western Sichuan plateau and the comparative analysis of the existing meteorological data, the corresponding relationships between the three parameters and the altitude were investigated. The thresholds by altitude for grading the tunnels are identified as $2100 \mathrm{~m}$ and $4200 \mathrm{~m}$, respectively. The highway tunnels in the western Sichuan plateau are graded in three categories, namely, general-altitude tunnels, high-altitude tunnels, and ultra-high-altitude tunnels. The corresponding measures of oxygen supply and freezing prevention for different graded tunnels are recommended. The results would provide a basis for the design and construction of new tunnels and enhance the service life and operations safety of the tunnels in western Sichuan plateau and other similar high-altitude areas.
\end{abstract}

Keywords: high altitude; environmental adaptive; vocational health; highway tunnel construction

\section{Introduction}

Tunnels are very important for transportation in mountain areas as they can significantly reduce transportation time and enhance transportation safety. Especially in high-altitude areas where transportation is prohibited by ice and snow in winter, tunnels may make road transportation possible. However, tunnel construction in high-altitude mountain areas may cause severe vocational health problems for the workers [1] and damage to the vulnerable ecological environment [2], which make the construction extremely difficult and expensive. The main challenges for tunnel construction in this area are as follows. Worker's health and efficiency are significantly influenced by low oxygen concentration and low temperature; machines and equipment also operate at low efficiency; extra designs such as deep-buried ditches are required to prevent damage of freezing [3-5]. As a result, there are not many such projects in construction. At present, no design code for high-altitude tunnel construction has been widely adopted. On the other hand, the economic development in western Sichuan plateau now generates a strong demand for transportation infrastructure. As more high-altitude highway tunnels 
are in design and construction in this area, there is an urgent need to study the different construction conditions for tunnels in such areas to increase construction efficiency, protect vocational health, and reduce environmental damage.

To cope with these challenges, various solutions such as artificial oxygen supply and extra heating are proposed. These solutions incur significant costs and thus should be implemented after careful consideration of local conditions and engineering requirements. The altitude of highway tunnels in western Sichuan plateau ranges from $500 \mathrm{~m}$ to $4400 \mathrm{~m}$ above sea level, and the construction conditions may vary significantly. We attempt to establish a simple grading rule for the tunnels to guide the construction design. The grading is based on analyzing oxygen deficiency and cold climate, which are key factors in high-altitude tunnels, through on-site meteorological monitoring. Since these two factors are closely related to altitude, we will use altitude as the grading criteria. Such a grading rule will be easy to implement, balance costs and efficiency, and guarantee project quality.

There already exist several grading standards for oxygen deficiency by altitude. For example, physiologists usually define altitude between 8000 and 12,000 feet (2438 m-3658 m) as high altitude, define altitude between 12,000 and 18,000 feet (3658 m-5487 m) as very high altitude, and define altitude above 18,000 feet (5487 $\mathrm{m}+$ ) as extremely high altitude, according to Cleveland Clinic [6]. Yang et al. [7] divide altitudes into five grades according to human habitation sustainability, in which over $3600 \mathrm{~m}$ is the top grade, at which people are likely to have high-altitude problems. These grading standards are usually established in a laboratory environment. Nevertheless, high-altitude tunnel construction requires a heavy workload. For example, tunnel boring machine (TBM) that is widely used in city tunnel construction cannot be deployed for constructing high-altitude tunnels because it would very often get jammed by mountain rocks. Workers need to dig with equipment in hand. The work is usually done in a natural environment, where microclimate often changes due to different elevation, slope, solar radiation, cloud cover, and soil type [8]. Thus, the existing altitude grading standards may not be suitable in tunnel construction. Yang et al. [9] and Yuan [10] measure oxygen content at a particular high-altitude tunnel construction site and provide suggestions for artificial oxygen supply. But their results are collected from a single tunnel. The generality remains to be verified. It is still not clear how to overcome oxygen deficiency for tunnel construction at different altitudes.

The existing design code also has grading standards for cold climate, but the grading is not in altitude. For example, the manual for highway tunnel design in China grades regions by mean temperature in the coldest month and maximum freezing depth [11]. There are similar gradings in design codes for the railway tunnel and civil building $[12,13]$. These grading standards are usually established in high-latitude areas and are applied to grade a region based on meteorological data from its town area. However, western Sichuan plateau locates in low-latitude area, and the climate may change significantly even within a small region because of dramatically changing altitude and other terrain factors [14]. The meteorological data outside town area are usually unavailable. If the meteorological data in town area is used instead to guide the construction of tunnels in mountains, the errors in meteorological information may cause damage in tunnel structure [15] or extra construction cost [16]. It is, in fact, not the region but every tunnel that needs to be graded in western Sichuan plateau. However, precise information on temperature and freezing depth at the tunnel location requires meteorological monitoring for a long period, which may delay the construction period $[17,18]$. The altitude becomes a promising quick grading criterion for cold climate at the tunnel location as temperatures and maximum freezing depths are closely related to it. Until now, the relationship between the altitude and important indicators such as the temperature and the maximum freezing depth has not been verified in western Sichuan plateau.

In this paper, we verify the changing patterns of oxygen deficiency and cold climate as altitude ascends on the basis of meteorological monitoring near the portals of three representative tunnels in western Sichuan plateau. We use atmospheric pressure to indirectly measure oxygen deficiency. The oxygen concentration of the air remains constant at different altitudes, which is about $20.9 \%$ of the total of the air (mainly nitrogen and oxygen). But atmospheric pressure decreases as altitude ascends. As a result, the partial pressure of oxygen and the absolute amount of oxygen decreases when 
the atmospheric pressure decreases. The oxygen deficiency caused by low atmospheric pressure is the main reason for mountain sickness, and at extreme conditions, may cause fatal problems $[19,20]$. The change in oxygen concentration by altitude fits the theoretical model very well. To ensure tunnel construction efficiency and safety, we quantitatively evaluate hypoxia risks at different altitudes and propose grading rules based on our data, literature, and existing regulations. On the other hand, the changes in the temperature and freezing depth have considerable variations. After combining the data analysis and real practice of tunnel construction, it is appropriate to classify the tunnels in western Sichuan plateau into three grades, that is, general-altitude tunnel, high-altitude tunnel, and ultra-high-altitude tunnel. The thresholds for altitude grading are identified as $2100 \mathrm{~m}$ and $4200 \mathrm{~m}$, respectively. The thresholds are relatively conservative and the corresponding construction measures recommended can protect vocational health and balance efficiency and cost.

Western Sichuan plateau plays an important role in China's tunnel construction. Western Sichuan plateau is a plateau area located at about $28^{\circ}-34^{\circ}$ north latitude, $97^{\circ}-104^{\circ}$ east longitude. The average altitude of western Sichuan plateau is above $3000 \mathrm{~m}$. Its area is about 300,000 square kilometers. Currently, more than $50 \%$ of China's tunnels with altitude above $2500 \mathrm{~m}$ are in western Sichuan plateau [21-23]. As No. 317 and No. 318 national highways expand, which are the two main highways in the Western Sichuan Plateau, the number and length of high-altitude tunnels keep increasing in this area. Our study focuses on western Sichuan plateau but may provide insights for tunnel construction in other similar high-altitude areas.

The rest of this paper is organized as follows. Section 2 describes the methods and data. Section 3 analyzes the grading of oxygen deficiency for highway tunnel construction in western Sichuan plateau. Section 4 analyzes the grading of cold climate for highway tunnel construction in western Sichuan plateau. Section 5 summarizes the grading standard and corresponding design codes for tunnel construction. Section 6 concludes the paper.

\section{Methods and Data}

We chose three long highway tunnels in western Sichuan plateau, namely Queershan Tunnel, Balangshan Tunnel, and Zheduoshan Tunnel, at which to perform on-site meteorological monitoring. The locations of these tunnels are demonstrated in Figure 1. The altitude of the three tunnels ranges from $3760 \mathrm{~m}$ to $4380 \mathrm{~m}$.

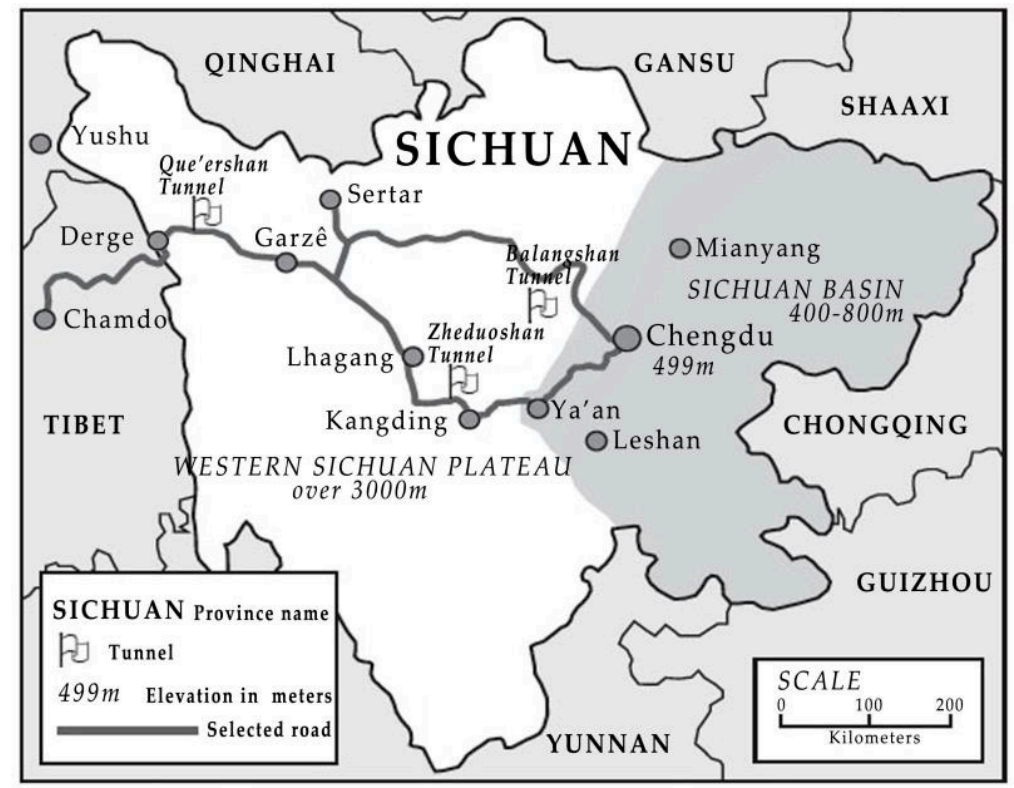

Figure 1. Schematic diagram of tunnel location. 
We recorded the atmospheric pressure, temperature, and freezing depth near the three tunnels for a period of 3 to 6 years. It was a long observation for tunnel construction projects. These three variables were chosen according to the practice of tunnel construction in a high-altitude area. Atmospheric pressure determines oxygen partial pressure, which influences labor efficiency and vocational health. The monthly average temperature is required by the technical specifications for design and construction of highway in seasonally frozen soil regions from Ministry of Transport of China [24]. It is defined as the average of temperatures at 2:00, 8:00, 14:00, and 20:00 over one month in the regulation [24]. The data of temperatures at other times were used for validation of records with large deviations. Outliers were removed. These are standard procedures in meteorological observations. The monthly average temperature in the coldest month (usually in January) and the maximum freezing depth are important for anti-freezing designs and construction of tunnels. At last, the data were compared with available long-term meteorological records over the last 30 years at nearby meteorological stations. The years monitored were typical of the expected weather conditions.

The data of atmospheric pressure and temperature were captured by AWSTJ-3 automatic meteorological station using VaisalaQML sensor modules from a Finnish company. The station is demonstrated in Figure 2. The observations were made every minute during the observation periods. Its measuring range and accuracy are summarized in Table 1 . The freezing depth was measured by rulers when observing the distance in the frost tube, buried vertically in the soil from the soil surface to the boundary between ice layer and unfrozen water.

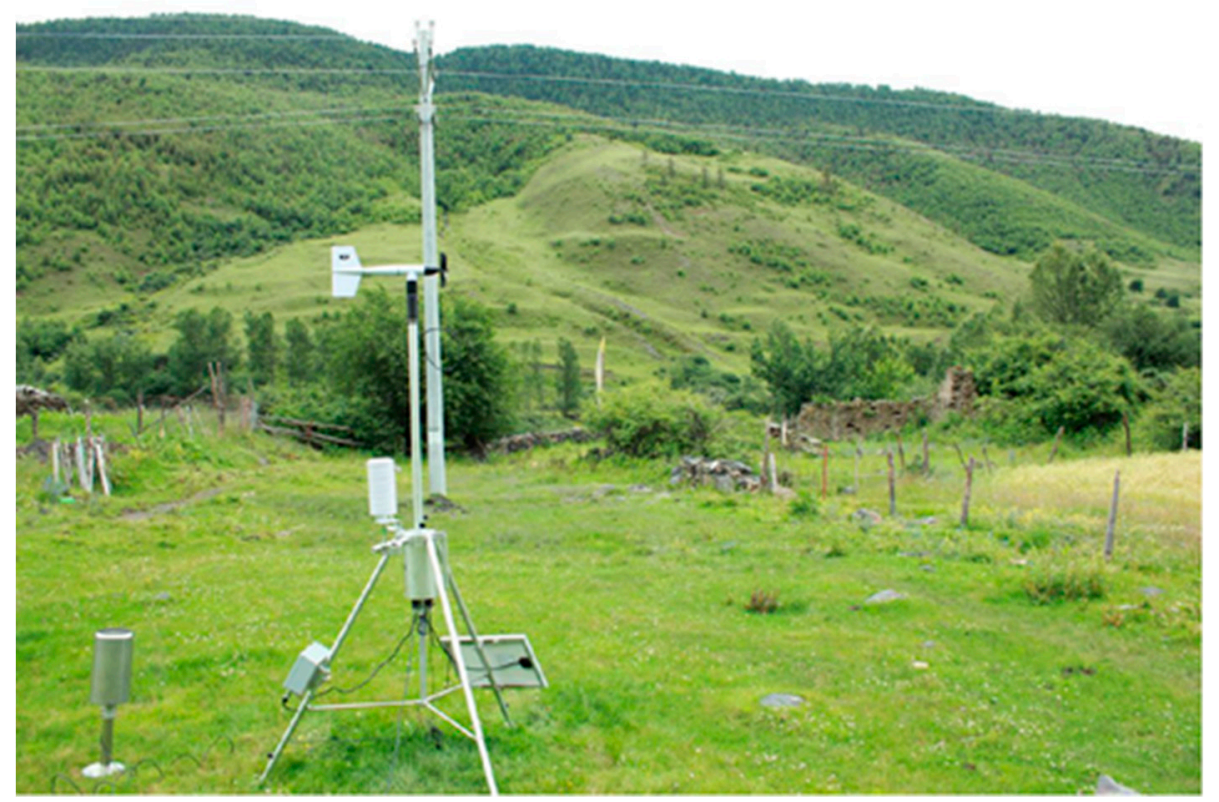

Figure 2. AWSTJ-3 automatic meteorological station at Zheduoshan Mountain.

Table 1. Measuring range and accuracy of AWSTJ-3 station.

\begin{tabular}{cccc}
\hline Variable & Measuring Range & Resolution & Error \\
\hline atmospheric pressure & $450 \mathrm{hPa}-1060 \mathrm{hPa}$ & $0.1 \mathrm{hPa}$ & $\pm 0.3 \mathrm{hPa}$ \\
temperature & $-50{ }^{\circ} \mathrm{C}-+60{ }^{\circ} \mathrm{C}$ & $0.1^{\circ} \mathrm{C}$ & $\pm 0.2^{\circ} \mathrm{C}$ \\
\hline
\end{tabular}

The corresponding theoretic models describing the relationship between altitude and these recorded variables were then compared with our observations. Considering the microclimate at the tunnel location, the relationships between altitude and oxygen deficiency and the relationships between altitude and coldness were established and calibrated for western Sichuan plateau. After that, we proposed a grading standard for tunnels by altitude considering vocational health, labor efficiency, and costs, and recommended appropriate design codes for tunnels of different grades. At last, the 
applicability of the grading standard was verified by measuring the workers' performance and the quality of tunnels.

\subsection{Queershan Tunnel}

Queershan Tunnel is located in Dege County, western Sichuan. The altitudes of its two portals are $4380 \mathrm{~m}$ and $4260 \mathrm{~m}$, respectively. The length of this tunnel is $7079 \mathrm{~m}$. The design of this tunnel began in 2002. We established monitoring points on the two sides of Queershan Mountain from $3800 \mathrm{~m}$ to $5200 \mathrm{~m}$ in altitude. A typical monitoring point is demonstrated in Figure 3a. The construction of Queershan Tunnel was completed in 2017. The portal of the tunnel is shown in Figure 3b.

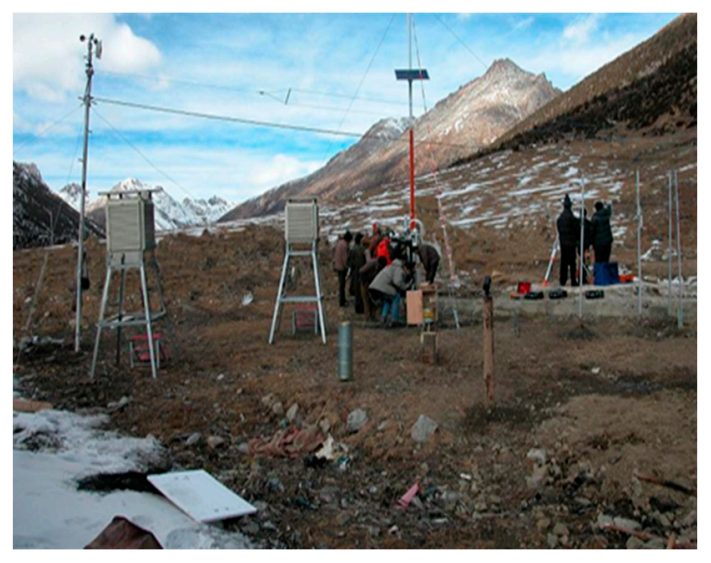

(a)

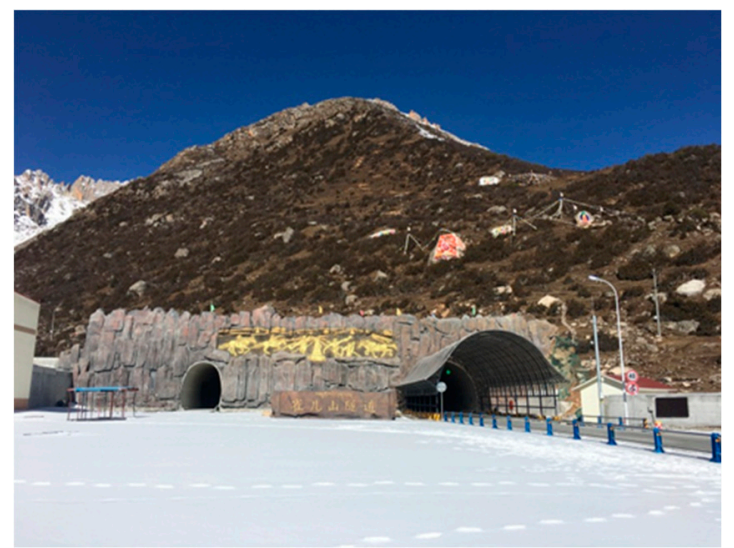

(b)

Figure 3. (a) One meteorological monitoring point in Queershan Mountain; (b) Portal of Queershan Tunnel.

We recorded the atmospheric pressure, temperature, and freezing depth at the monitoring points. The monitoring lasted for 6 years, from 2005 to 2010. The average values of meteorological monitoring results for every $100 \mathrm{~m}$ in altitude are reported in Table 2.

Table 2. Meteorological monitoring results of Queershan tunnel.

\begin{tabular}{ccccccc}
\hline Altitude & \multicolumn{2}{c}{ Atmospheric Pressure (kPa) } & \multicolumn{2}{c}{$\begin{array}{c}\text { Mean Temperature in the } \\
\text { Coldest Month }\left({ }^{\circ} \mathbf{C}\right)\end{array}$} & $\begin{array}{c}\text { Maximum Freezing Depth } \\
(\mathbf{c m})\end{array}$ \\
\hline $\mathbf{( m )}$ & East Side & West Side & East Side & West Side & East Side & West Side \\
\hline 3800 & 64.26 & 64.11 & -6.3 & -6.4 & 105 & 106 \\
3900 & 63.49 & 63.36 & -6.8 & -7.0 & 110 & 111 \\
4000 & 62.73 & 62.61 & -7.4 & -7.6 & 114 & 115 \\
4100 & 61.96 & 61.87 & -7.9 & -8.2 & 119 & 120 \\
4200 & 61.20 & 61.13 & -8.5 & -8.8 & 123 & 124 \\
4300 & 60.44 & 60.38 & -9.0 & -9.4 & 127 & 129 \\
4400 & 59.69 & 59.64 & -9.6 & -10.0 & 132 & 133 \\
4500 & 58.93 & 58.90 & -10.0 & -10.6 & 136 & 138 \\
4600 & 58.18 & 58.17 & -10.7 & -11.2 & 141 & 142 \\
4700 & 57.44 & 57.43 & -11.3 & -11.8 & 145 & 147 \\
4800 & 56.69 & 56.69 & -11.8 & -12.4 & 150 & 151 \\
4900 & 55.95 & 55.97 & -12.4 & -13.0 & 154 & 155 \\
5000 & 55.21 & 55.25 & -12.9 & -13.6 & 158 & 160 \\
5100 & 54.48 & 54.54 & -13.5 & -14.2 & 163 & 164 \\
5200 & 53.75 & 53.82 & -14.1 & -14.7 & 167 & 169 \\
\hline
\end{tabular}

Queershan Mountain is a typical mountain in western Sichuan plateau with mountain monsoon climate. There is a clear dry season and rainy season, and local weather changes dramatically. 
As altitude ascends, the temperature declines at a rate of $0.55-0.65{ }^{\circ} \mathrm{C} / 100 \mathrm{~m}$. The freezing depth at the tunnel is more than $120 \mathrm{~cm}$.

\subsection{Balangshan Tunnel}

Balangshan Tunnel is located in Xiaojin County, western Sichuan. The altitudes of its two portals are $3845 \mathrm{~m}$ and $3852 \mathrm{~m}$, respectively. The length of this tunnel is $7954 \mathrm{~m}$. We established monitoring points on the two sides of Balangshan Mountain from altitude $3200 \mathrm{~m}$ to $4200 \mathrm{~m}$. A typical monitoring point is demonstrated in Figure 4a. The construction of Balangshan Tunnel was completed in 2016. The portal of the tunnel is shown in Figure $4 b$.

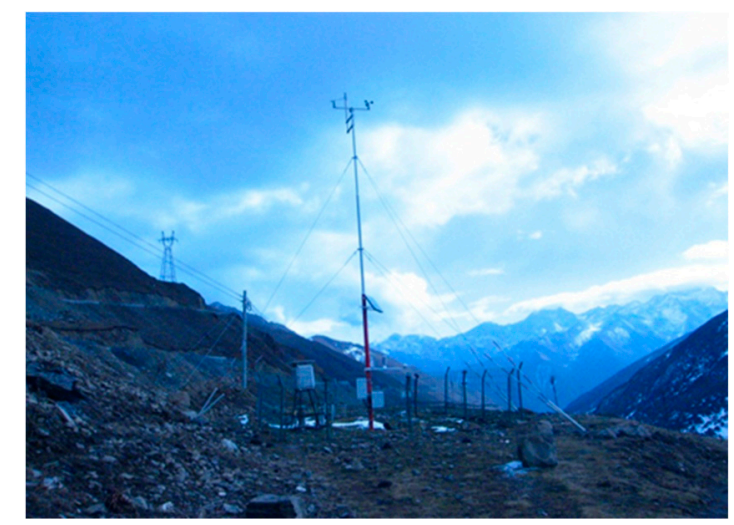

(a)

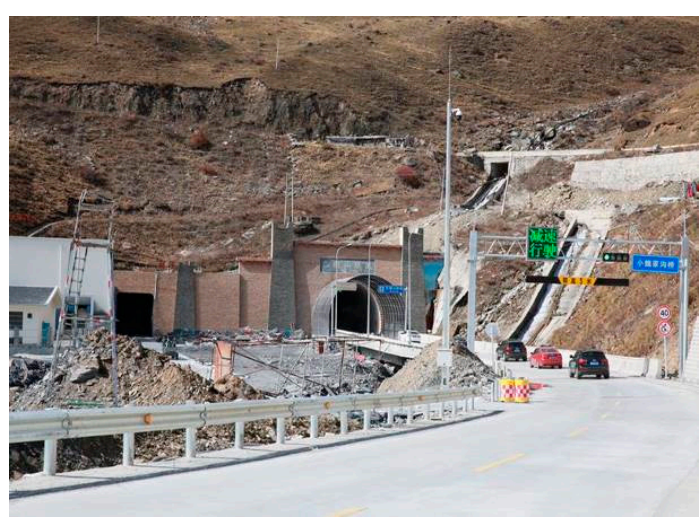

(b)

Figure 4. (a) One meteorological monitoring point in Balangshan Mountain; (b) Portal of Balangshan Tunnel.

Similarly, we recorded the atmospheric pressure, temperature, and freezing depth at the observation points. The monitoring lasted for 3 years, from 2009 to 2011 . The average values of meteorological monitoring results every $100 \mathrm{~m}$ in altitude are reported in Table 3.

Table 3. Meteorological monitoring results of Balangshan tunnel.

\begin{tabular}{ccccccc}
\hline Altitude & \multicolumn{2}{c}{ Atmospheric Pressure (kPa) } & \multicolumn{2}{c}{$\begin{array}{c}\text { Mean Temperature in the } \\
\text { Coldest Month }\left({ }^{\circ} \mathbf{C}\right)\end{array}$} & \multicolumn{2}{c}{$\begin{array}{c}\text { Maximum Freezing Depth } \\
(\mathbf{c m})\end{array}$} \\
\hline $\mathbf{( m )}$ & East Side & West Side & East Side & West Side & East Side & West Side \\
\hline 3200 & 68.27 & 68.39 & -5.4 & -4.2 & 67 & 67 \\
3300 & 67.57 & 67.69 & -5.9 & -4.7 & 76 & 75 \\
3400 & 66.88 & 66.99 & -6.4 & -5.2 & 84 & 84 \\
3500 & 66.18 & 66.29 & -6.9 & -5.7 & 92 & 92 \\
3600 & 65.49 & 65.60 & -7.4 & -6.2 & 100 & 100 \\
3700 & 64.80 & 64.90 & -7.9 & -6.7 & 109 & 109 \\
3800 & 64.10 & 64.20 & -8.4 & -7.2 & 117 & 117 \\
3900 & 63.41 & 63.50 & -8.9 & -7.7 & 125 & 125 \\
4000 & 62.71 & 62.80 & -9.4 & -8.2 & 134 & 133 \\
4100 & 62.02 & 62.10 & -9.9 & -8.7 & 142 & 142 \\
4200 & 61.32 & 61.40 & -10.4 & -9.2 & 150 & 150 \\
\hline
\end{tabular}

Balangshan Mountain also has a clear dry season and rainy season. The mountain climate is significant with obvious vertical climate differences. The temperature decreases at a rate of about $0.6^{\circ} \mathrm{C} / 100 \mathrm{~m}$ as altitude increases. There are some differences between the two sides of the mountain. But the climate patterns are similar. 


\subsection{Zheduoshan Tunnel}

Zheduoshan Tunnel is located in Yulin Town. The altitudes of its two portals are $3760 \mathrm{~m}$ and $3880 \mathrm{~m}$, respectively. The length of this tunnel is $8427 \mathrm{~m}$. We established monitoring points on the two sides of Zheduoshan Mountain from $3400 \mathrm{~m}$ to $4200 \mathrm{~m}$. The construction of Zheduoshan Tunnel began in 2018. Now, it is still in the construction process.

The monitoring lasted for 3 years, from 2012 to 2015. The average atmospheric pressure, temperature, and freezing depth every $100 \mathrm{~m}$ in altitude are reported in Table 4.

Table 4. Meteorological monitoring results of Zheduoshan tunnel.

\begin{tabular}{ccccccc}
\hline Altitude & \multicolumn{2}{c}{ Atmospheric Pressure (kPa) } & \multicolumn{2}{c}{$\begin{array}{c}\text { Mean Temperature in the } \\
\text { Coldest Month }\left({ }^{\circ} \mathbf{C}\right)\end{array}$} & $\begin{array}{c}\text { Maximum Freezing Depth } \\
(\mathbf{c m})\end{array}$ \\
\hline $\mathbf{( m )}$ & East Side & West Side & East Side & West Side & East Side & West Side \\
\hline 3400 & 66.80 & 66.87 & -4.8 & -5.1 & 75 & 67 \\
3500 & 65.90 & 66.20 & -5.2 & -5.7 & 79 & 70 \\
3600 & 65.20 & 65.40 & -6.2 & -6.2 & 83 & 74 \\
3700 & 64.40 & 64.50 & -7.2 & -6.7 & 87 & 78 \\
3800 & 63.95 & 63.97 & -8.2 & -7.0 & 91 & 82 \\
3900 & 63.57 & 63.67 & -9.2 & -7.7 & 95 & 86 \\
4000 & 63.10 & 62.95 & -9.7 & -8.2 & 101 & 90 \\
4100 & 62.87 & 62.55 & -10.8 & -8.7 & 106 & 94 \\
4200 & 62.56 & 62.23 & -11.3 & -9.2 & 110 & 98 \\
\hline
\end{tabular}

The climate at Zheduoshan Tunnel has a similar pattern as Queershan Tunnel and Balangshan Tunnel. The temperature on the west side is slightly higher than on the east side and drops more slowly as altitude ascends. The maximum freezing depth is larger on the east side than on the west side. The differences are because of changes in microclimate near the tunnel influenced by elevation, slope, solar radiation, cloud cover, soil type, and so forth.

In summary, the three tunnels share similar mountain monsoon climate though located hundreds of kilometers away and at different altitudes. There are minor differences in atmospheric pressure, temperature, and freezing depth, but the patterns as altitude ascends are similar. These data provide a basis for our grading analysis.

\section{Grading Oxygen Deficiency for Highway Tunnel Construction in Western Sichuan Plateau}

The grading of oxygen deficiency in tunnel construction is based on the performance of labor efficiency and vocational health. As altitude ascends, oxygen deficiency will cause a decrease in labor efficiency and even severe health problems.

The oxygen partial pressure is regarded as the main indicator of oxygen deficiency. It can be calculated using atmospheric pressure. The formula of calculation is shown in Equation (1).

$$
\mathrm{P}_{\mathrm{O} 2}=\mathrm{F}_{\mathrm{O} 2}(\mathrm{P}-6.27)
$$

where $\mathrm{P}_{\mathrm{O} 2}$ represents the oxygen partial pressure in $\mathrm{kPa}, \mathrm{F}_{\mathrm{O} 2}$ is the oxygen concentration, and $\mathrm{P}$ is the atmospheric pressure in $\mathrm{kPa}$ [25]. Consequently, the equivalent sea-level oxygen concentration at atmospheric pressure $\mathrm{P}$ can be calculated as

$$
\mathrm{F}^{\prime} \mathrm{O} 2=(\mathrm{P}-6.27) \times 20.9 \% /(101.325-6.27)
$$

We compared the data in Tables 1-3 to the model in U.S. Standard Atmosphere 1976 [26]. The data fits the model very well, and the relationship between atmospheric pressure and altitude can be expressed in Equation (3) and Figure 5. 


$$
\mathrm{P}=101.325 \times(1-\mathrm{h} / 44329)^{5.1}
$$

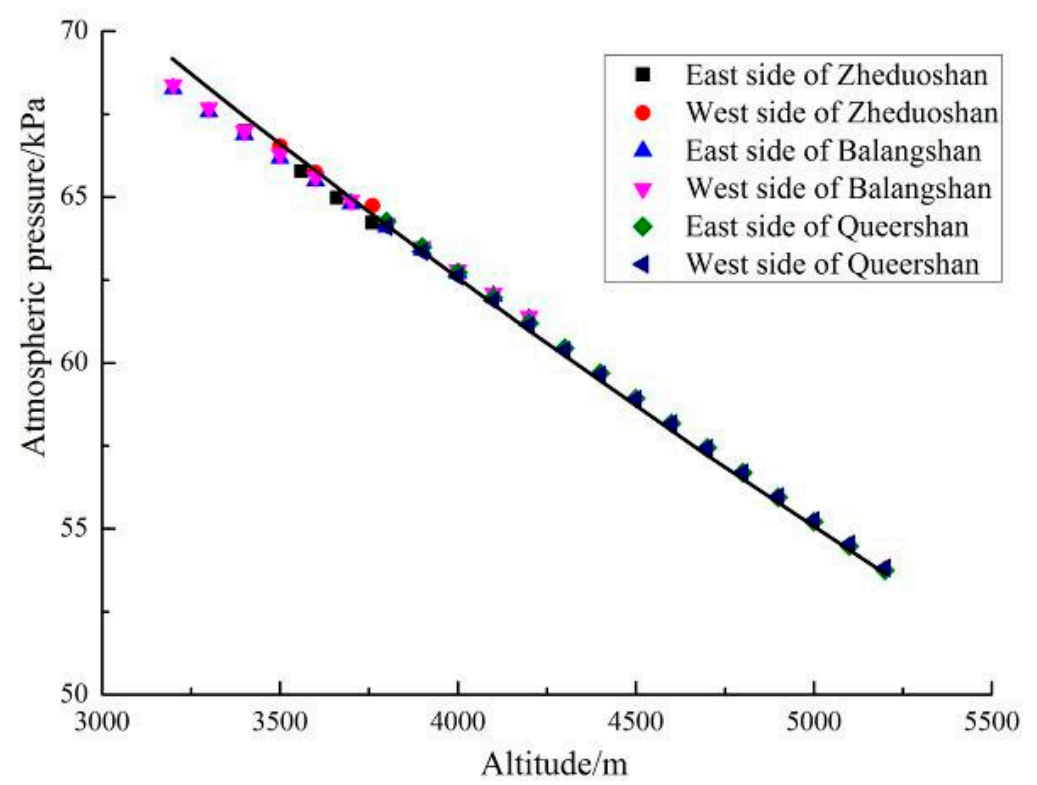

Figure 5. Relationship between atmospheric pressure and altitudes.

The variable $h$ represents the altitude in meters. The standard error of the estimated coefficient of 5.1 is 0.011 , thus the coefficient is significant ( $p$-value $<0.05$ ). The adjusted R-square for this nonlinear regression is 0.99508 .

Our grading standard is based on the effects of acute exposure to oxygen-deficient atmospheres on human beings [27]. The physiological effects are summarized in Table 5.

Table 5. Physiological effects of acute exposure to oxygen-deficient atmospheres.

\begin{tabular}{lc}
\hline \multicolumn{1}{c}{ Effect } & $\begin{array}{c}\text { Equivalent Sea-Level Oxygen } \\
\text { Concentration (\%) }\end{array}$ \\
\hline No symptoms & $16-20.9$ \\
\hline $\begin{array}{l}\text { Increased heart and breathing rate, some loss of coordination, increased } \\
\text { breathing volume, impaired attention and thinking }\end{array}$ & 16 \\
\hline $\begin{array}{l}\text { Abnormal fatigue upon exertion, emotional upset, faulty coordination, } \\
\text { impaired judgment }\end{array}$ & 14 \\
\hline $\begin{array}{l}\text { Very poor judgment and coordination, impaired respiration that may } \\
\text { cause permanent heart damage, nausea, and vomiting }\end{array}$ & 12 \\
\hline $\begin{array}{l}\text { Nausea, vomiting, lethargic movements, perhaps unconsciousness, } \\
\text { inability to perform vigorous movement or loss of all movement, } \\
\text { unconsciousness followed by death }\end{array}$ & $<10$ \\
\hline
\end{tabular}

In many countries including China, the legal oxygen concentration limit for workplace exposure is $19.5 \%$ [28]. According to the physiological effects, we identify $16 \%$ and $12 \%$ as another two critical thresholds for labor efficiency and vocational health in tunnel constructions. If the equivalent sea-level oxygen concentration is less than $16 \%$, there is slight oxygen deficiency and labor efficiency will be negatively affected. According to the experience in construction projects with oxygen deficiency, the workers' labor time reduces from $8 \mathrm{~h}$ per day to about $5 \mathrm{~h}$ per day. If the equivalent sea-level oxygen concentration is less than $12 \%$, then there is severe oxygen deficiency and the workers' health will 
be damaged. Consequently, $12 \%, 16 \%$, and $19.5 \%$ of equivalent sea-level oxygen concentration were selected as our grading thresholds.

By Equations (2) and (3), we translated the oxygen concentration into atmospheric pressure, and then into altitude. The altitude $600 \mathrm{~m}$ corresponds to the oxygen concentration of $19.5 \%$. The altitude of $2100 \mathrm{~m}$ corresponds to the oxygen concentration of $16 \%$. And the altitude $4200 \mathrm{~m}$ corresponds to the oxygen concentration of $12 \%$. Tunnels at different altitudes will be graded at different categories. The grading of oxygen deficiency for tunnels by altitude is summarized in Table 6 .

Table 6. Oxygen deficiency for tunnel construction at different altitudes in western Sichuan plateau.

\begin{tabular}{cccc}
\hline Altitude (m) & $\begin{array}{c}\text { The Oxygen Partial Pressure } \\
\text { of Trachea (kPa) }\end{array}$ & $\begin{array}{c}\text { Equivalent Sea-Level } \\
\text { Oxygen Concentration (\%) }\end{array}$ & Level of Oxygen Deficiency \\
\hline$<600$ & $>18.44$ & $>19.5$ & No oxygen deficiency \\
$600-2100$ & $15.22-18.44$ & $16-19.5$ & Slight oxygen deficiency \\
$2100-4200$ & $11.44-15.22$ & $12-16$ & Medium oxygen deficiency \\
$>4200$ & $<11.44$ & $<12$ & Severe oxygen deficiency \\
\hline
\end{tabular}

Guo et al. [29] provided a similar grading standard of oxygen deficiency for tunnel construction through theoretical analysis. By contrast, our thresholds in altitude for grading oxygen deficiency are based on field data observed at the tunnel location. Compared with their grading thresholds $2500 \mathrm{~m}$ and $4500 \mathrm{~m}$, our thresholds $2100 \mathrm{~m}$ and $4200 \mathrm{~m}$ are more conservative. This difference is because the observed atmospheric pressure under $3500 \mathrm{~m}$ in western Sichuan plateau is slightly lower than the theoretical prediction, thus the oxygen partial pressure is lower. And, we prefer to be more conservative when defining the altitude threshold which threatens workers' health.

\section{Grading of Cold Climate for Highway Tunnel Construction in Western Sichuan Plateau}

Cold climate is another main challenge for tunnel construction at high altitude. In order to adapt to the cold climate, more engineering work such as insulation or deep draining system is required, thus increases the cost and burden to the local ecological environment. The grading of the cold climate is based on the average temperature of the coldest month and the maximum freezing depth. As altitude ascends, the average temperature of the coldest month will decrease and the maximum freezing depth will increase. To control tunnel construction cost and environmental burden, we quantitatively measured coldness at different altitudes and propose grading rules based on our data, literature, and existing design codes.

We ran regressions using the data in Tables 2-4 to evaluate the relationship between coldness and altitude in western Sichuan plateau. The results are demonstrated in Figure 6.

At the locations of all the tunnels, the average temperature of the coldest month decreases linearly in altitude. According to the U.S. Standard Atmosphere 1976, the temperature decreases by $0.65^{\circ} \mathrm{C}$ every $100 \mathrm{~m}$ higher for altitudes below $11,000 \mathrm{~m}$ [26]. From the data of the three tunnels, we found the temperature decreasing rate is between $0.55^{\circ} \mathrm{C}$ to $0.65{ }^{\circ} \mathrm{C}$ per $100 \mathrm{~m}$, which is very close to the existing model predictions, but there are minor variations at different tunnels. The altitude-temperature relationship can be represented by the following equation after regression,

$$
\mathrm{T}=-0.0056 \times \mathrm{h}+13.535
$$

where $\mathrm{T}$ represents the average temperature of the coldest month in ${ }^{\circ} \mathrm{C}, \mathrm{h}$ is the altitude in meters. The standard error of the estimated slope is $2.26 \times 10^{-5}$, thus the coefficient is significant ( $p$-value $<0.05$ ). The adjusted R-square is 0.99729 . The simple linear equation fits the data very well, and the line of Equation (4) is drawn in Figure 6a.

According to Code for Thermal Design of the Civil Building in China (GB50176-2016), regions with the average temperature in the coldest month less than $-10^{\circ} \mathrm{C}$ are classified as severe cold area, regions with the average temperature in the coldest month between $0{ }^{\circ} \mathrm{C}$ and $-10^{\circ} \mathrm{C}$ are cold area [30]. This is 
a conservative standard compared with other design codes. We used the two threshold temperatures $0{ }^{\circ} \mathrm{C}$ and $-10{ }^{\circ} \mathrm{C}$ to derive the threshold altitudes. From Equation (4), the altitudes which correspond to temperature $0{ }^{\circ} \mathrm{C},-10^{\circ} \mathrm{C}$ are approximately $2400 \mathrm{~m}, 4200 \mathrm{~m}$, respectively.

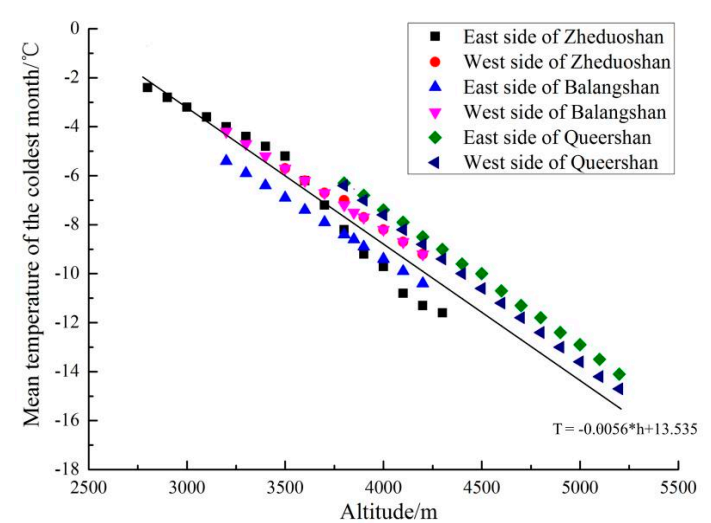

(a)

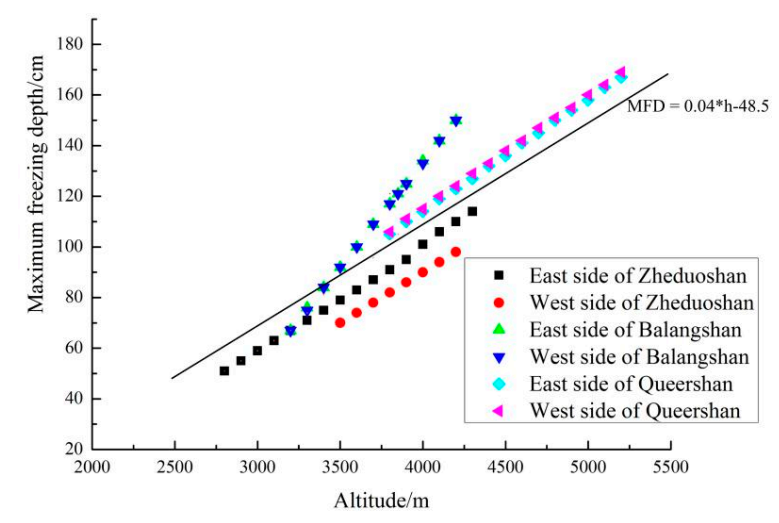

(b)

Figure 6. (a) The relationship between mean temperature of the coldest month and altitude;

(b) The relationship between maximum freezing depth and altitude.

The maximum freezing depth directly determines the effort required in the construction. For example, if the maximum freezing depth is large, the ditches should be buried deeper to avoid damages from freezing. The maximum freezing depth depends on many factors such as the local climatic conditions, the heat transfer properties of the soil and construction materials, and nearby heat sources. As far as we know, there is no simple formula describing the relationship between maximum freezing depth and altitude. As demonstrated in Figure 6b, the six groups of data monitored at the three tunnels show that the maximum freezing depth also decreases linearly in altitude. We conjecture that at least in western Sichuan plateau, this linear relationship is common at different tunnels. However, both the slope and intercept of the linear functions vary within a considerable range at different locations. It may be caused by nearby terrestrial heat or different types of soil. The relationship between altitude and maximum freezing depth is estimated by the following equation after regression,

$$
\mathrm{MFD}=0.04 \times \mathrm{h}-48.5
$$

where MFD is the maximum freezing depth in centimeters, $\mathrm{h}$ is the altitude in meters. The standard error of the estimated slope is $4.04 \times 10^{-4}$, thus the coefficient is significant ( $p$-value $<0.05$ ). The adjusted $\mathrm{R}$-square is 0.99487. The linear Equation (5) fits the data very well and is drawn in Figure $6 \mathrm{~b}$.

The grading of maximum freezing depth in existing design codes for highway and railway tunnels in China cannot be applied directly in western Sichuan plateau because those standards are mainly for high-latitude areas. The maximum freezing depth is significantly smaller in low-latitude areas such as western Sichuan plateau. We thus derived the thresholds to grade maximum freezing depth from construction practice using the relationship between altitude and maximum freezing depth.

In the practice of tunnel construction in western Sichuan plateau, there are two kinds of ditches in the design, as shown in Figure 7. One is an ordinary ditch buried at the depth of $50 \mathrm{~cm}-65 \mathrm{~cm}$, which is used in an ordinary environment. The other is deep-buried ditch at the depth of $150 \mathrm{~cm}-200 \mathrm{~cm}$, which is used in a severe-cold environment. If the ditch is buried shallower than the maximum freezing depth, it may be frozen and stops functioning (see Figure 8). We used these depths to derive the corresponding threshold altitudes. To be conservative, we used the lower bound depths $50 \mathrm{~cm}$ and $150 \mathrm{~cm}$ to derive the corresponding threshold altitudes. Because the thermal conductivity of concrete is higher than soil, the freezing depths in concrete are about 1.3 times larger than the freezing depths in 
the soil. Hence the freezing depths $50 \mathrm{~cm}$ and $150 \mathrm{~cm}$ in concrete were transformed to freezing depths $38 \mathrm{~cm}$ and $115 \mathrm{~cm}$ in soil. We used Equation (5) to derive conservative thresholds to grade altitudes. The altitudes which correspond to maximum depths $38 \mathrm{~cm}$ and $115 \mathrm{~cm}$ are approximately $2100 \mathrm{~m}$ and $4300 \mathrm{~m}$, respectively.

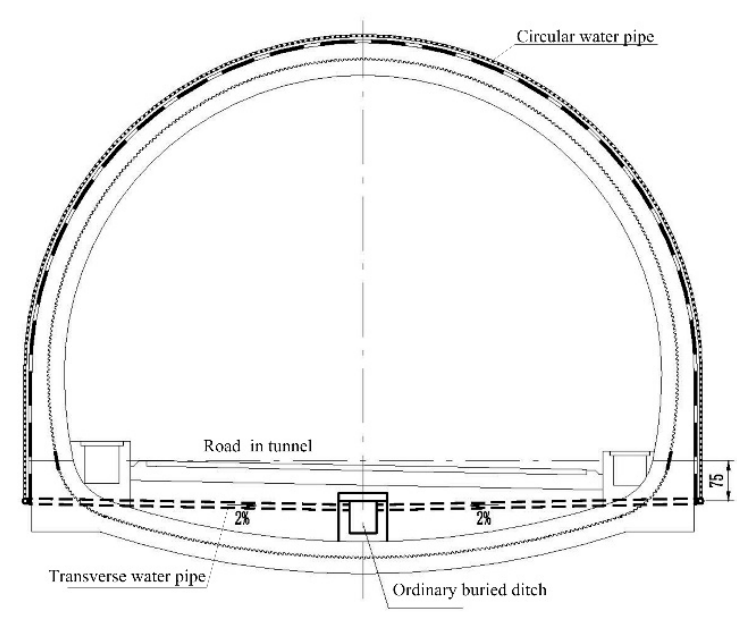

(a)

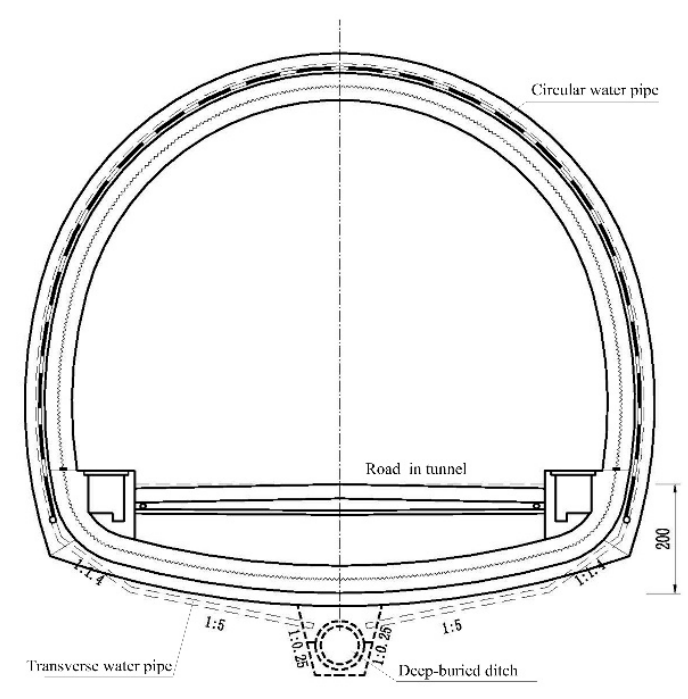

(b)

Figure 7. (a) Ordinary ditch; (b) Deep-buried ditch.

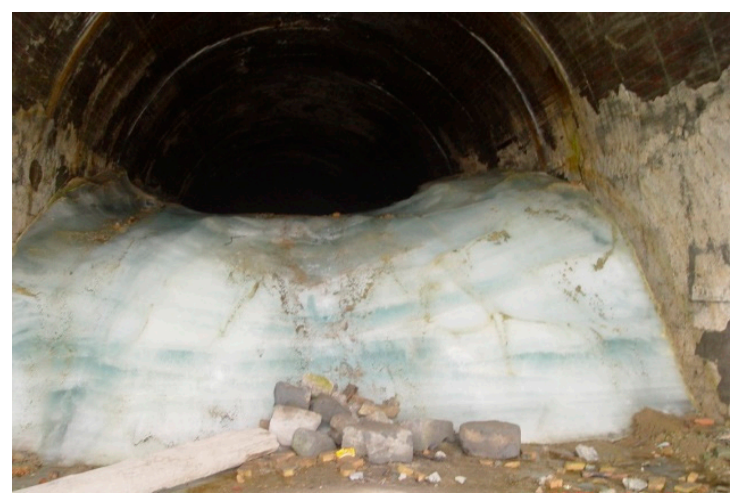

Figure 8. A frozen tunnel when ditches are frozen.

The ditch should be buried below the maximum freezing depth, otherwise, it may be damaged after freezing. According to our grading using maximum freezing depth data, it is safe to use ordinary ditch for tunnels below $2100 \mathrm{~m}$ in altitude and to use deep-buried ditch for tunnels between $2100 \mathrm{~m}$ and $4300 \mathrm{~m}$ in altitude.

To guarantee the service life and operations safety of the tunnel, we took the minimum of the thresholds derived from the two variables of coldness as a conservative standard. Tunnels below $2100 \mathrm{~m}$ were categorized as in an ordinary environment. Tunnels between $2100 \mathrm{~m}$ and $4200 \mathrm{~m}$ were categorized as in a cold environment. Tunnels above $4200 \mathrm{~m}$ were categorized as in a severely cold environment.

\section{Recommendations for Graded Tunnel Construction in Western Sichuan Plateau}

Through grading the oxygen deficiency level and coldness, we concluded that the altitudes $2100 \mathrm{~m}$ and $4200 \mathrm{~m}$ are important thresholds which may be used to guide different construction measures. We classified tunnels lower than $2100 \mathrm{~m}$ as ordinary-altitude tunnels, defined tunnels between $2100 \mathrm{~m}$ 
and $4200 \mathrm{~m}$ as high-altitude tunnels, and defined tunnels above $4200 \mathrm{~m}$ as ultra-high-altitude tunnels. The results are summarized in Table 7.

Table 7. Tunnel grading by altitudes in western Sichuan plateau.

\begin{tabular}{cccc}
\hline Tunnel Classification & Altitude(m) & Level of Oxygen Deficiency & Level of Coldness \\
\hline Ordinary tunnel & $<2100$ & Slight oxygen deficiency & Ordinary \\
High-altitude tunnel & $2100-4200$ & Medium oxygen deficiency & Cold \\
Ultra-high-altitude tunnel & $>4200$ & Severe oxygen deficiency & Severe cold \\
\hline
\end{tabular}

We verified the grading standard by further observations in the tunnels. According to Table 7 , Queershan Tunnel is graded as an ultra-high-altitude tunnel and Balangshan Tunnel and Zheduoshan Tunnel are graded as high-altitude tunnels. Three workers were enrolled in the verification process as subjects. Their physiological performance was measured when they were working at the bottom of Zheduoshan mountain, at Balangshan Tunnel, and at Queershan Tunnel. The heart rate and arterial pressure were measured by Omron HEM-7201 blood pressure monitor. The accuracy of the heart rate is $\pm 5 \%$, and the precision of arterial pressure is $\pm 3 \mathrm{mmHg}$ of reading. The saturation of blood oxygen was measured by Likang POD2 blood oxygen saturation monitor. The accuracy of $\mathrm{SaO} 2$ is $\pm 2 \%$ of reading. Each worker was measured three times at one location. The results are summarized in Table 8 .

Table 8. Physiological performance of tunnel workers in western Sichuan plateau.

\begin{tabular}{cccccc}
\hline Location & Altitude (m) & $\begin{array}{c}\text { Equivalent Sea-Level } \\
\text { Oxygen } \\
\text { Concentration (\%) }\end{array}$ & $\begin{array}{c}\text { Saturation of Blood } \\
\text { Oxygen (SaO2, \%) }\end{array}$ & $\begin{array}{c}\text { Heart Rate } \\
\text { (BPM) }\end{array}$ & $\begin{array}{c}\text { Mean Arterial } \\
\text { Pressure (mmHg) }\end{array}$ \\
\hline Sea-level & 50 & 20.9 & $97.23 \pm 1.36$ & $77.6 \pm 8.37$ & $87.5 \pm 12.83$ \\
Balangshan Tunnel & 3850 & 12.5 & $85 \pm 3.25$ & $87 \pm 7.64$ & $98.5 \pm 6.83$ \\
Queershan Tunnel & 4380 & 11.6 & $77.85 \pm 6.02$ & $91.7 \pm 10.07$ & $102.0 \pm 8.24$ \\
\hline
\end{tabular}

Table 8 shows that at high-altitude tunnels, the saturation of blood oxygen drops by about $12 \%$, the heart rate and the arterial pressure increase by about $12 \%$ compared with the data at sea-level locations. It was observed that the workers needed to rest more frequently and the labor efficiency was significantly lower. At ultra-high-altitude tunnels, the saturation of blood oxygen drops by about $20 \%$, the heart rate and the arterial pressure increase by about $18 \%$ and $17 \%$. According to Shen et al.'s study on workers' performance in the construction of plateau railway, when $\mathrm{SaO}_{2} \%$ drops to $75 \%-80 \%$, the muscle functioning is influenced and there are lethal risks [31]. We observed that in the ultra-high-altitude tunnel, the workers could not continue working without support in oxygen supply. This was not a formal physiological study. Only three workers took part in the measurement at the three locations. Since the subjects were limited, we were not able to establish any statistical robustness from the data. It just provides several representative cases/examples of workers at different graded tunnels, which partially support the grading threshold we proposed.

The grading of tunnels is also safe for the cold climate in western Sichuan plateau. According to the operations records of the existing tunnels in western Sichuan plateau, the anti-freezing measures for different grades of tunnels function very well. No significant damage to the tunnel itself and the ecological environment has been observed.

We make the following suggestions for tunnel construction work, combining the altitude grading standard and our work experience on existing tunnels.

The ordinary tunnel construction does not require extra oxygen supply or anti-freezing measures. The level of oxygen deficiency is slight that it does not affect labor efficiency. The level of coldness does not affect the normal functioning of the draining system.

The high-altitude tunnel construction should be supported by oxygen supply for workers and anti-freezing measures. We recommend using diffusive oxygen supply in partial places of the tunnel to maintain labor efficiency and using insulation for ditches and portals to prevent freezing problems. 
Such measures can effectively support labor efficiency [32] and prevent water leakage outside the tunnel, thus reduce the impact on the local ecological environment.

The ultra-high-altitude tunnel construction requires a comprehensive oxygen supply mechanism, which consists of partial diffusive oxygen supply and personal mask oxygen supply. Meanwhile, the ultra-high-altitude tunnel also requires integrated anti-freezing and frost resistance measures such as insulation, deeply buried ditch, surrounding rock grouting, and antifreeze lining. With these measures, the labor efficiency can be maintained at a much lower but acceptable level. As a result, the duration of construction will be extended by approximately $20 \%$. The costs for vocational health protection and anti-freezing measures also increase significantly for ultra-high-altitude tunnels, by about $20 \%$ compared with similar tunnels at the sea level. There will be great challenges for design and construction, thus we suggest avoiding tunnel construction in altitudes above $4200 \mathrm{~m}$.

The suggestions and their achieved improvements are summarized in Table 9.

Table 9. Suggestions for constructing tunnels of different grades.

\begin{tabular}{cccc}
\hline Tunnel Classification & $\begin{array}{c}\text { Artificial Oxygen } \\
\text { Supply }\end{array}$ & Anti-Freezing Measures & Improvements \\
\hline Ordinary tunnel & Not required & Not required & - \\
\hline High-altitude tunnel & diffusive oxygen supply & $\begin{array}{c}\text { Insulation for ditches and } \\
\text { portals }\end{array}$ & $\begin{array}{c}\text { Maintain labor efficiency, } \\
\text { less environmental impact }\end{array}$ \\
\hline $\begin{array}{c}\text { Ultra-high-altitude } \\
\text { tunnel }\end{array}$ & $\begin{array}{c}\text { comprehensive oxygen } \\
\text { supply mechanism }\end{array}$ & $\begin{array}{c}\text { insulation, deeply buried ditch, } \\
\text { surrounding rock grouting and } \\
\text { anti-freeze lining }\end{array}$ & $\begin{array}{c}\text { Maintain labor health, resist } \\
\text { frost }\end{array}$ \\
\hline
\end{tabular}

\section{Conclusions}

To cope with challenges from oxygen deficiency and coldness in highway tunnel construction in western Sichuan plateau, we provide a simple grading rule of tunnels by altitude to guide the construction process. The grading rule is derived by analyzing the oxygen partial pressure of trachea, the mean temperature of the coldest month, and the maximum freezing depth for tunnel projects after on-site meteorological monitoring. These three variables exhibit a good linear relationship with altitudes, thus can be graded through one altitude variable.

The critical threshold altitudes for tunnel grading, $2100 \mathrm{~m}$ and $4200 \mathrm{~m}$, are consistent with existing design codes but can be used to provide more guidance for oxygen supply and anti-freezing engineering in high-altitude tunnel construction. Different means are recommended for ordinary tunnels, high-altitude tunnels, and ultra-high-altitude tunnels, respectively. The results may help to accelerate new tunnel construction at high altitudes by avoiding long-term meteorological monitoring while controlling vocational health risks and project quality. The grading standard of tunnels by altitude can be easily applied in future tunnel construction in western Sichuan plateau area and other areas with a similar environment.

Author Contributions: Conceptualization, J.Z.; methodology, F.Y.; validation, P.W. and Y.W.; formal analysis, J.Z., F.Y. and P.W.; writing-original draft preparation, F.Y. and P.W.; writing-review and editing, P.W.

Funding: This research was funded by National Natural Science Foundation of China, grant number 51804261 and Department of Science and Technology of Sichuan Province, grant number 2019YJ0556.

Conflicts of Interest: The authors declare no conflict of interest. The funders had no role in the design of the study; in the collection, analyses, or interpretation of data; in the writing of the manuscript, or in the decision to publish the results.

\section{References}

1. West, J.B. The physiologic basis of high-altitude diseases. Ann. Intern. Med. 2004, 141, 789-800. [CrossRef] [PubMed]

2. Ye, F.; He, C.; Wang, S.; Zhang, J.-l. Landscape design of mountain highway tunnel portals in China. Tunn. Undergr. Space Technol. 2012, 29, 52-68. [CrossRef] 
3. Wang, M.N.; Li, Q.; Yu, L.; He, J.; Cai, M. Development of new technologies for ventilation, oxygen supply, disaster prevention and energy saving for high-altitude tunnels. Tunn. Constr. 2017, 37, 1209-1216.

4. Zhu, Y.Q.; Jia, X.Y.; Zhang, X.Y. Circumstances controlling technology of high altitude tunnel during construction in permafrost regions. Rock Soil Mech. 2006, 27, 2177-2180.

5. Wang, S.J.; Wang, Z.; Yuan, K.; Zhao, Y.Z. Qinghai Tibet highway engineering geology in permafrost regions: Review and prospect. China J. Highw. Transp. 2015, 28, 1-8.

6. Altitude Sickness. Available online: https://my.clevelandclinic.org/health/diseases/15111-altitude-sickness (accessed on 9 September 2019).

7. Yang, H.Y. A Study on the Classification of Human Habitation Suitability in China. Ph.D. Thesis, Nanjing Normal University, Nanjing, China, 2013.

8. Bramer, I.; Anderson, B.J.; Bennie, J.; Bladon, A.J.; De Frenne, P.; Hemming, D.; Hill, R.A.; Kearney, M.R.; Körner, C.; Korstjens, A.H.; et al. Advances in monitoring and modelling climate at ecologically relevant scales. Adv. Ecol. Res. 2018, 58, 101-161.

9. Yang, F.; Zheng, J.L.; Wei, Y.Q.; Wu, J.; Li, Y.W. Oxygen content change and oxygen supply method in high altitude tunnel construction. Sci. Technol. Eng. 2013, 19, 282-288.

10. Yuan, Q. Actual Measurement and Design of Individual Oxygen Supply at High-Altitude Highway Tunnel in Balang Mountain. Northern Communi. 2015, 6, 117-120.

11. Liao, C.H.; Guo, X.H. Manual for Design of Highway Tunnel; China Communications Press: Beijing, China, 2012.

12. Lin, W.S. Manual for Design of Railway Tunnel; China Railway Publishing House: Beijing, China, 1995.

13. National Railway Administration. Code for Design of Railway Tunnel: TB 10003-2016[S]; China Railway Publishing House: Beijing, China, 2016.

14. Potter, K.A.; Arthur Woods, H.; Pincebourde, S. Microclimatic challenges in global change biology. Glob. Chang. Biol. 2013, 19, 2932-2939. [CrossRef] [PubMed]

15. Zhang, S.; Lai, Y.; Zhang, X.; Pu, Y.; Yu, W. Study on the damage propagation of surrounding rock from a cold-region tunnel under freeze-thaw cycle condition. Tunn. Undergr. Space Technol. 2004, 19, $295-302$. [CrossRef]

16. Petroutsatou, K.; Georgopoulos, E.; Lambropoulos, S.; Pantouvakisv, J.P. Early cost estimating of road tunnel construction using neural networks. J. Constr. Eng. Manag. 2012, 138, 679-687. [CrossRef]

17. Zhang, Y.W.; Lai, J.X.; Qiu, J.L.; Xie, Y.L. Test and analysis on frost heaven effects of cold region tunnel. J. Traffic Transp. Eng. 2018, 18, 64-73.

18. Li, Y.M. Experimental Study on Frost Heaving Force of Surrounding Rock. Ph.D. Thesis, Jilin University, Changchun, China, 2018.

19. Zhou, Z.N. Review of studies on hypoxic physiology. Adv. Physiol. Sci. 2012, 43, 1-4.

20. Dai, X.Y.; Wang, Z.; Liu, T. Evaluation of the influence of plateau on human healthiness in China. J. Mt. Sci. 2006, 24, 312-319.

21. Wang, Y.; Gao, J.R.; Zhang, B. Study of influence of harmful exhaust of tunnel construction machinery in high-altitude areas and its countermeasures. Tunn. Constr. 2016, 36, 717-720.

22. Li, Y.Y.; Zhang, Y.W.; Zhao, Y.W.; Li, Y. Temperature test and frost analysis of cold regional rich water tunnel at high altitudes on the western of Sichuan province. J. Railw. Sci. Eng. 2018, 15, 1778-1785.

23. Zheng, J.L.; Li, Y.W.; Deng, G.; Weng, H.M. Measurement of the altitude coefficients for Queershan Tunnel. Mod. Tunn. Technol. 2007, 44, 10-15.

24. Ministry of Transport of China. Technical Specifications for Design and Construction of Highway in Seasonal Frozen Soil Region: JTG/T D31-06-2017; China Communications Press: Beijing, China, 2017.

25. Woerlee, G.M. Calculation of Expected PaO2. In Common Perioperative Problems and the Anaesthetist; Woerlee, G.M., Ed.; Springer: Dordrecht, The Netherlands, 1988; pp. 154-156.

26. U.S. Standard Atmosphere 1976. Available online: https://ntrs.nasa.gov/search.jsp?R=19770009539 (accessed on 9 September 2019).

27. McManus, N. Oxygen: Health Effects and Regulatory Limits; Northwest Occupational Health \& Safety: North Vancouver, BC, Canada, 2009.

28. State Administration of Work Safety. Safety Regulation for Working under Hazardous Condition of the Oxygen Deficiency: GB 8958-2006; Standards Press of Beijing: Beijing, China, 2006. 
29. Guo, C.; Xu, J.F.; Wang, M.N.; Yan, T.; Yang, L.; Sun, Z. Study on oxygen supply standard for physical health of construction personnel of high-altitude tunnels. Int. J. Environ. Res. Public Health 2016, 13, 64. [CrossRef] [PubMed]

30. Ministry of Housing and Urban-Rural Development of People's Republic of China. Code for Thermal Design of Civil Building: GB 50176-2016; China Architecture \& Building Press: Beijing, China, 2016.

31. Shen, Q.; Sun, Y.J.; Qi, Y.; Liu, J.L.; Xu, Y. The decrease of arterial oxygen saturation predict the susceptibility of pulmonary edema at high altitude. J. Med. Res. 2009, 38, 29-31.

32. Wang, M.; Yan, G.; Yu, L.; Xie, W.; Dai, Y. Effects of different artificial oxygen-supply systems on migrants' physical and psychological reactions in high-altitude tunnel construction. Build. Environ. 2019, 149, 458-467. [CrossRef]

(C) 2019 by the authors. Licensee MDPI, Basel, Switzerland. This article is an open access article distributed under the terms and conditions of the Creative Commons Attribution (CC BY) license (http://creativecommons.org/licenses/by/4.0/). 